\title{
The Effect of Glycinebetaine Priming on Seed Germination of Six Turfgrass Species under Drought, Salinity, or Temperature Stress
}

\author{
Qi Zhang' and Kevin Rue \\ Department of Plant Sciences, North Dakota State University, Department \\ \#7670, P.O. Box 6050, Fargo, ND 58108
}

\section{Jeanna Mueller North Dakota State Seed Department, P.O. Box 5257, Fargo, ND 58105}

Additional index words. abiotic stress, seed priming, germination rate

\begin{abstract}
Glycinebetaine (GB) seed priming enhances stress tolerance in various plants during the germination and seedling growth stage; however, information regarding turfgrass is limited. In this study, GB at 5 to $50 \mathrm{~mm}$ was used to prime seeds of six turfgrass species to evaluate the potential of GB priming in enhancing tolerance to drought, salinity, and sub-optimal temperature during germination. Stress tolerance was determined as relative final germination percentage (FGP) and daily germination percentage (DGP), expressed as percentage of germination under stress conditions compared with the control treatment (i.e., unprimed seeds germinated under non-stress condition) for each species. Daily germination percentage was more sensitive to stress than FGP. Perennial ryegrass (Lolium perenne L.) showed high tolerance to drought, salinity, and chilling temperatures $\left(5\right.$ and $10{ }^{\circ} \mathrm{C}$ below optimal germination temperature) followed by tall fescue (Festuca arundinacea Schreb.) and creeping bentgrass (Agrostis palustris L.), whereas kentucky bluegrass (Poa pratensis L.), bermudagrass [Cynodon dactylon var. dactylon (L.) Pers.], and zoysiagrass (Zoysia japonica Steud.) were stresssensitive. Kentucky bluegrass and bermudagrass showed higher germination at $10 \mathrm{~mm}$ GB under temperature stress and drought and temperature stresses, respectively; however, other grasses showed limited responses to seed priming. Our results showed that the efficacy of GB priming is plant-, GB concentration-, and stressor-dependent.
\end{abstract}

Plant growth and development is affected by various environmental stresses such as drought, salinity, and suboptimal temperatures. During the seed germination and seedling growth stages, plants are the most vulnerable to stresses (Almansouri et al., 2001). Rapid and uniform seed germination will help plants establish a healthy stand. Seed priming has been used to enhance seed germination and seedling growth in various plants (Farooq et al., 2006). During the priming period, seed is hydrated with water (i.e., hydropriming) or other solutions. The embryo is pre-enlarged and the germination rate is enhanced (Austin et al., 1969; Gray and Steckel, 1977). Research shows that seed priming enhances germination in many crops, especially under environmental stress conditions. For instance, Zheng et al. (1994) reported that hydroprimed canola (Brassica

\footnotetext{
Received for publication 8 Aug. 2014. Accepted for publication 9 Sept. 2014.

We extend our gratitude to the U.S. Golf Association and the ND Hatch ND01540 for funding this research. We also appreciate the valuable suggestions and comments from Drs. Alan Zuk and Esther McGinnis during the preparation of this manuscript. ${ }^{1}$ To whom reprint requests should be addressed; e-mail qi.zhang.1@ndsu.edu.
}

(Helianthus annuus L.) under saline and drought conditions (Kaya et al., 2006). Polyethelene glycol 8000 (PEG8000)-primed soybean (Glycine max L.) showed enhanced seed germination and growth under chilling conditions ( $\mathrm{Li}$ et al., 2010). However, excess priming may interrupt enzyme activity, resulting in poor germination and abnormal growth (Ajouri et al., 2004; Farooq et al., 2006).

Glycinebetaine (GB) is the most abundant osmoprotectant produced in plants in response to dehydration induced by drought, salinity, and suboptimal temperatures (Ashraf and Foolad, 2007; Chen and Murata, 2008). Accumulation of GB under stressful environmental conditions has been well documented in many plants including barley (Hordeum vulgare L.) (Nomura et al., 1995), wheat (Triticum aestivum L.) (Naidu et al., 1991), and sorghum [Sorghum bicolor (L.) Moench] (Weimberg et al., 1984). Non- or low-GBaccumulating plants showed enhanced stress tolerance upon the transformation of genes regulating the GB-synthesis pathway (Ashraf and Foolad, 2007; Sakamoto and Murata, 1999). Furthermore, exogenous applications of GB improved the chilling tolerance in tomato (Solanum lycopersicum L.) (Park et al., 2006) and maize (Zea mays L.) (Farooq et al., 2008). Foliar applications of GB also significantly increased salinity tolerance in creeping bentgrass (Agrostis palustris L.) (CB), kentucky bluegrass (Poa pratensis L.) $(\mathrm{KB})$, and perennial ryegrass (Lolium perenne L.) (PR) (Hu et al., 2012; Yang et al., 2012). Ashraf and Foolad (2007) reported that GB had multiple functions such as adjusting osmotic potential $\left(\psi_{\mathrm{S}}\right)$, protecting enzyme and membrane integrity, stabilizing enzymes and proteins, and detoxifying reactive oxygen in plants grown under abiotic stress conditions. Recent reports also show that GB may have napus L.) seeds had a higher germination rate and stronger seedling vigor compared with the unprimed seeds under low-temperature conditions. Similar results were observed in hydroprimed and $\mathrm{KNO}_{3}$-primed sunflower

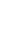

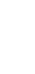

(n)

(n)

.


Table 2. Analysis of variance of final germination percentage (FGP) and daily germination rate (DGR) of unprimed and primed seeds of six turfgrass species under drought, salinity, and temperature stress.

\begin{tabular}{|c|c|c|c|c|c|c|c|c|c|c|c|}
\hline \multicolumn{4}{|c|}{ Drought } & \multicolumn{4}{|c|}{ Salinity } & \multicolumn{4}{|c|}{ Temperature } \\
\hline Source of variance & $\mathrm{df}$ & FGP & DGR & Source of variance & $\mathrm{df}$ & FGP & DGR & Source of variance & $\mathrm{df}$ & FGP & DGR \\
\hline$\overline{\text { Drought (D) }}$ & 3 & $* * *$ & $* * *$ & Salinity (S) & 4 & $* * *$ & $* * *$ & Temperature (T) & 4 & $* * *$ & $* * *$ \\
\hline Grass $(\mathrm{G})$ & 5 & $* * *$ & $* * *$ & Grass (G) & 5 & $* * *$ & $* * *$ & Grass $(\mathrm{G})$ & 5 & $* * *$ & $* * *$ \\
\hline Priming $(\mathrm{P})$ & 4 & NS & NS & Priming $(\mathrm{P})$ & 4 & NS & NS & Priming $(\mathrm{P})$ & 4 & NS & $*$ \\
\hline $\mathrm{G} \times \mathrm{D}$ & 15 & $* * *$ & $* * *$ & $\mathrm{G} \times \mathrm{S}$ & 20 & $* * *$ & $* * *$ & $\mathrm{G} \times \mathrm{T}$ & 20 & $* * *$ & $* * *$ \\
\hline $\mathrm{G} \times \mathrm{P}$ & 20 & $*$ & NS & $\mathrm{G} \times \mathrm{P}$ & 20 & NS & NS & $\mathrm{G} \times \mathrm{P}$ & 20 & $* * *$ & $* * *$ \\
\hline $\mathrm{D} \times \mathrm{P}$ & 12 & NS & NS & $\mathrm{S} \times \mathrm{P}$ & 16 & NS & NS & $\mathrm{T} \times \mathrm{P}$ & 16 & NS & NS \\
\hline $\mathrm{G} \times \mathrm{D} \times \mathrm{P}$ & 60 & NS & NS & $\mathrm{G} \times \mathrm{S} \times \mathrm{P}$ & 80 & NS & NS & $\mathrm{G} \times \mathrm{T} \times \mathrm{P}$ & 80 & NS & NS \\
\hline
\end{tabular}

${ }^{*},{ }^{* *}, * * *$ represent significant differences at the $0.05,0.01$, and $0.001 P$ level, respectively.

NS represented nonsignificant differences at the $0.05 P$ level.

$\mathrm{FGP}=$ final germination percentage; DGR = daily germination percentage.
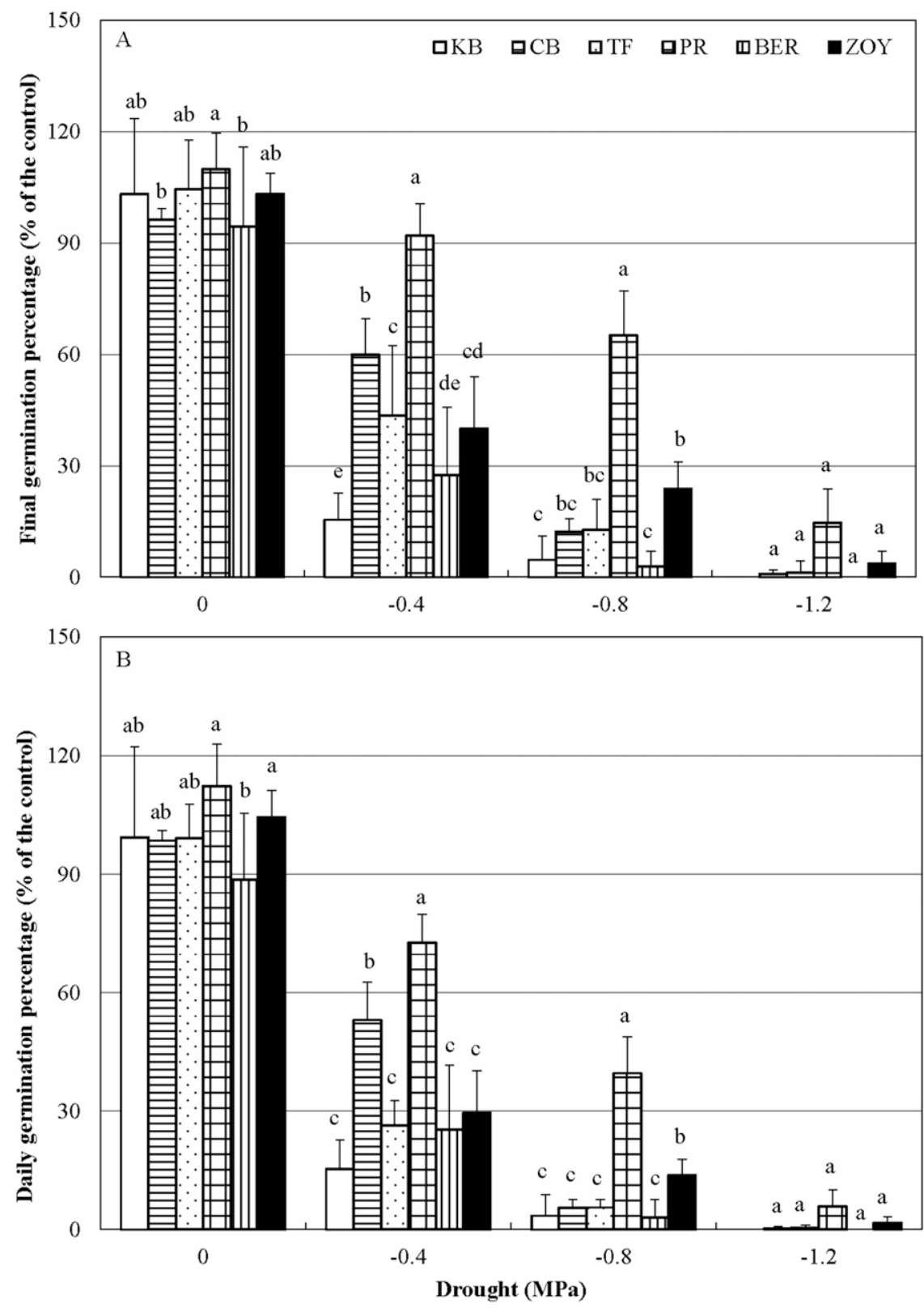

Fig. 1. Interactive effect of drought and turfgrass species on final germination percentage (A) and daily germination percentage (B). Turfgrass species included perennial ryegrass (PR), tall fescue (TF), creeping bentgrass $(\mathrm{CB})$, kentucky bluegrass $(\mathrm{KB})$, bermudagrass (BER), and zoysiagrass (ZOY). Data were presented as percentage of the control (unprimed seeds germinated at $0 \mathrm{MPa}$ ) of each species and averaged over priming treatments. Means followed by the same letter under each drought level were not significantly different $(P \leq 0.05)$. Vertical bar indicates SD of individual mean. a role in the salt overly sensitive pathway under salt stress (Ashraf and Foolad, 2007; Chinnusamy et al., 2005). Most of the aforementioned studies focused on the GB effects on mature plants. Studies on GB enhanced plant tolerance to abiotic stresses through seed priming, however, are limited (Farooq et al., 2008; Mahmood et al., 2009; Zhang and Rue, 2012). The objective of this study was to determine if GB seed priming has the potential to improve turfgrass tolerance of drought, salinity, and suboptimal temperatures.

\section{Materials and Methods}

Plant materials and seed priming. Six turfgrass species were included in this study: four cool-season grasses, 'Stonewall' tall fescue (Festuca arundinacea Schreb.) (TF), 'L-93' CB, 'Kenblue' KB, and 'Zoom' PR, and two warm-season grasses, 'Zenith' zoysiagrass (Zoysia japonica Steud.) (ZOY) and 'Riviera' bermudagrass [Cynodon dactylon var. dactylon (L.) Pers.] (BER). Seeds were soaked in continuously aerated deionized/ distilled water $\left(\mathrm{ddH}_{2} \mathrm{O}\right)$ or 5,10 , and $50 \mathrm{~mm}$ of GB for $24 \mathrm{~h}$ at $25 \pm 2{ }^{\circ} \mathrm{C}$ following the procedure used by Zhang and Rue (2012). Glycinebetaine concentrations were selected based on the results of a preliminary study in which the highest germination rate was obtained when seeds were primed with 10 mM GB under saline conditions (Table 1). The ratio of seed weight to solution volume was greater than 1:5 to ensure adequate quantity of solution for absorption (Farooq et al., 2006). Seeds were then rinsed three times with distilled water and air-dried to the original weight in a laminar-flow hood $(\approx 12 \mathrm{~h})$ in the dark. Unprimed seeds were also included in the experiment. Seeds of each grass (unprimed and primed) were surfacesterilized using the methods of Zhang et al. (2011) before the germination test under each stressful environment.

Expt. I: Priming effect on seed germination under drought stress. Forty unprimed or primed seeds of each grass were placed on a germination paper (Anchor Paper Company, St. Paul, MN) in a $100 \times 15-\mathrm{mm}$ petri dish. The germination paper was saturated with $10 \mathrm{~mL}$ of PEG6000 solution to provide drought condition (Emmerich and Hardegree, 1991). The level of drought stress was determined to 

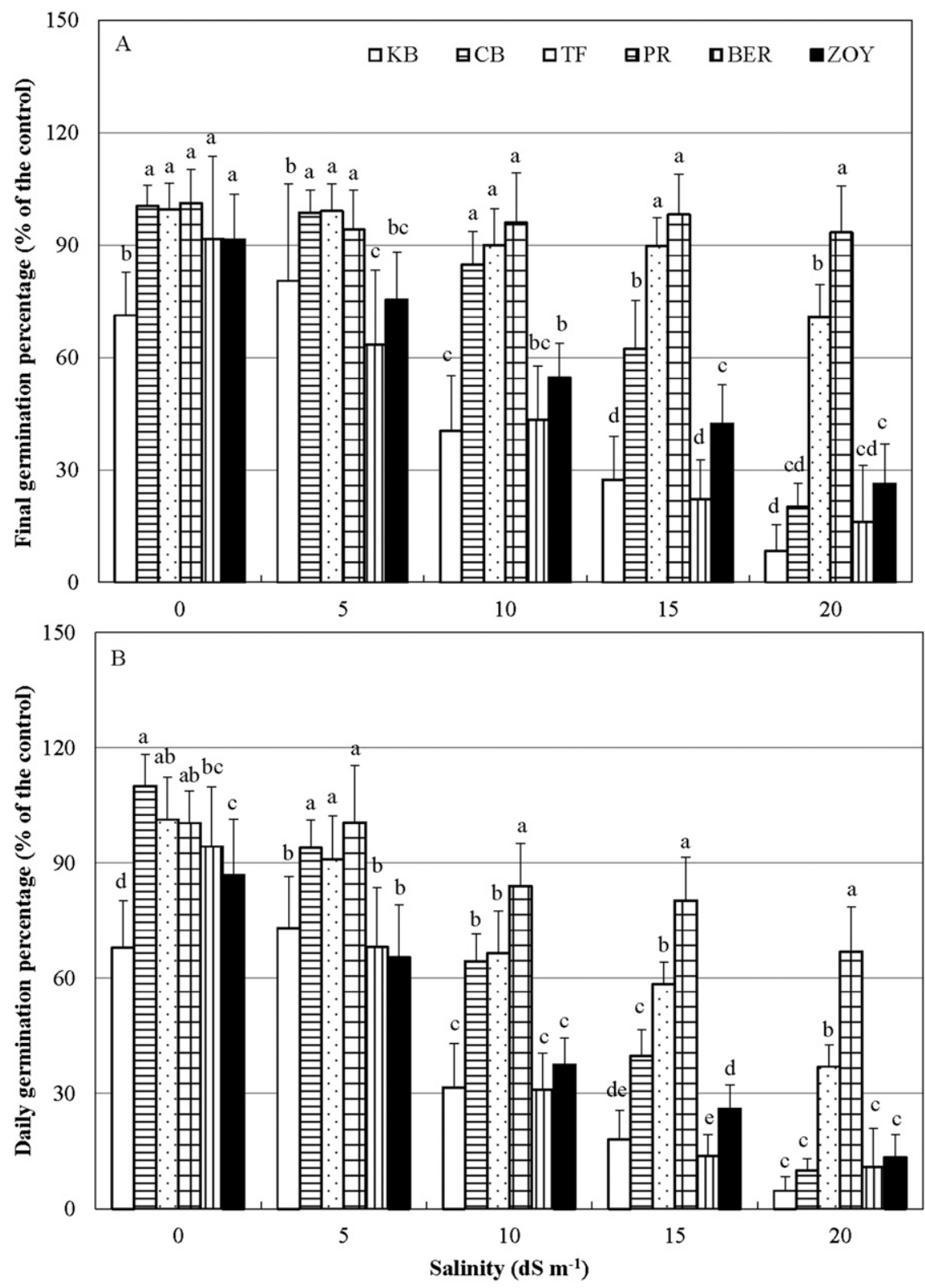

Fig. 2. Interactive effect of salinity and turfgrass species on final germination percentage (A) and daily germination percentage (B). Turfgrass species included perennial ryegrass (PR), tall fescue (TF), creeping bentgrass (CB), kentucky bluegrass (KB), bermudagrass (BER), and zoysiagrass (ZOY). Data were presented as percentage of the control (unprimed seeds germinated at $0.0 \mathrm{dS} \cdot \mathrm{m}^{-1}$ ) of each species and averaged over priming treatments. Means followed by the same letter under each salinity level were not significantly different $(P \leq 0.05)$. Vertical bar indicates SD of individual mean.

be $0.0,-0.4,-0.8$, or $-1.2 \mathrm{MPa}$ by calculating the $\psi_{\mathrm{S}}$ of PEP6000 solution following the method of Michel and Kaufmann (1973). Petri dishes were then sealed with parafilm and placed in a culture room at $25 \pm 2{ }^{\circ} \mathrm{C}$ under fluorescent light $\left(36 \mu \mathrm{mol} \cdot \mathrm{s}^{-1} \cdot \mathrm{m}^{-2}\right)$ with a $8 / 16-\mathrm{h}$ (light/dark) photoperiod. Environmental conditions were monitored with a HOBO Temp/RH/ Light data logger (Model U12-012; Onset Corp., Bourne, MA) at a 30-min interval during the experiment.

Expt. II: Priming effect on seed germination under salinity stress. Seeds of each grass (unprimed and primed) were placed in a $100 \times$ $15-\mathrm{mm}$ petri dish containing $20 \mathrm{~mL}$ of $1 \%$ agar (Sigma-Aldrich Co., St. Louis, MO) supplemented with $0,5,10,15$, or $20 \mathrm{dS} \cdot \mathrm{m}^{-1} \mathrm{NaCl}$
(36 $\left.\mu \mathrm{mol} \cdot \mathrm{s}^{-1} \cdot \mathrm{m}^{-2}\right)$ with a $8 / 16$-h $($ light/dark) photoperiod. The OPT for the cool-season grasses was $25 / 15^{\circ} \mathrm{C}$ (day/night) (Association of Official Seed Analysts, 2004). The OPT for the warm-season grasses was $30 / 20{ }^{\circ} \mathrm{C}$ (day/ night), different from that $\left(35 / 20^{\circ} \mathrm{C}\right)$ suggested by the Association of Official Seed Analysts (2004) to compensate the number of incubators used in the present study. This temperature setting $\left(30 / 20^{\circ} \mathrm{C}\right)$ was still within the optimal germination conditions for warm-season grasses with temperature ranging from 20 to $35{ }^{\circ} \mathrm{C}$ (Aldous, 1999). Conditions in incubators were monitored with $\mathrm{HOBO}$ Temp/RH/Light data loggers (Model U12-012, Onset Corp.) at a 30-min interval during the experiment.

Data collection and analysis. Seed germination, defined as an emerged shoot visible under $2 \times$ magnification, was counted and recorded three times weekly for 4 weeks (McCarty and Dudeck, 1993) in each experiment. FGP, representing total germination rate over a 4-week period, and DGP, representing germination rate over time, were calculated following the method of Zhang et al. (2011) in which FGP $(\%)=100 \times[(\Sigma n) / 40]$ and $\operatorname{DGP}\left(\% \mathrm{~d}^{-1}\right)=100 \times[\Sigma(n / D)] / 40$, respectively, where $n$ was the number of new seeds germinated at each counting and $D$ was the number of days accumulated up to that counting.

Expt. I was a six (turfgrass species) $\times$ four (seed priming treatment) $\times$ four (drought level) factorial design arranged in a randomized complete block design to minimize potential shelf effect (block) in the culture room. Each treatment had three replicates (petri dishes). Expt. II was identical to Expt. I in experimental design, except that five levels of salinity were included. Expt. III was arranged in a split-plot design. Whole plots were incubators (temperature regimes), where the subplot treatments [six (turfgrass species) $\times$ five (seed priming treatment) factorial combinations] were applied in separate incubators in a completely randomized design with three replications (petri dishes). The whole-plot treatment (temperature) had to be replicated sequentially in time (twice) rather than concurrently because of limited availability of incubators.

To avoid variations in seed size and seedling vigor in different turfgrass species, data of unprimed seeds germinated under non-stress conditions (i.e., the control treatment) were standardized as $100 \%$ for each species and other data were presented as percentage of the control within each species (Horst and Dunning, 1989). All data were subjected to PROC GLM (SAS Institute Inc., Cary, NC) to test treatment effects and means were separated with Fisher's protected least significant difference when a significant difference occurred $(P \leq 0.05)$.

\section{Results} were placed in a $100 \times 15-\mathrm{mm}$ petri dish containing $20 \mathrm{~mL}$ of $1 \%$ agar (Sigma-Aldrich Co.) medium as described in Expt. II and placed in incubators (Model SG30SC, Hoffman Manufacturing Inc., Jefferson, MO; Model GR-810, Percival Manufacturing Co., Boone, IW) at optimal temperatures (OPT), $\mathrm{OPT} \pm 5{ }^{\circ} \mathrm{C}$, and $\mathrm{OPT} \pm 10{ }^{\circ} \mathrm{C}$ under fluorescent light 

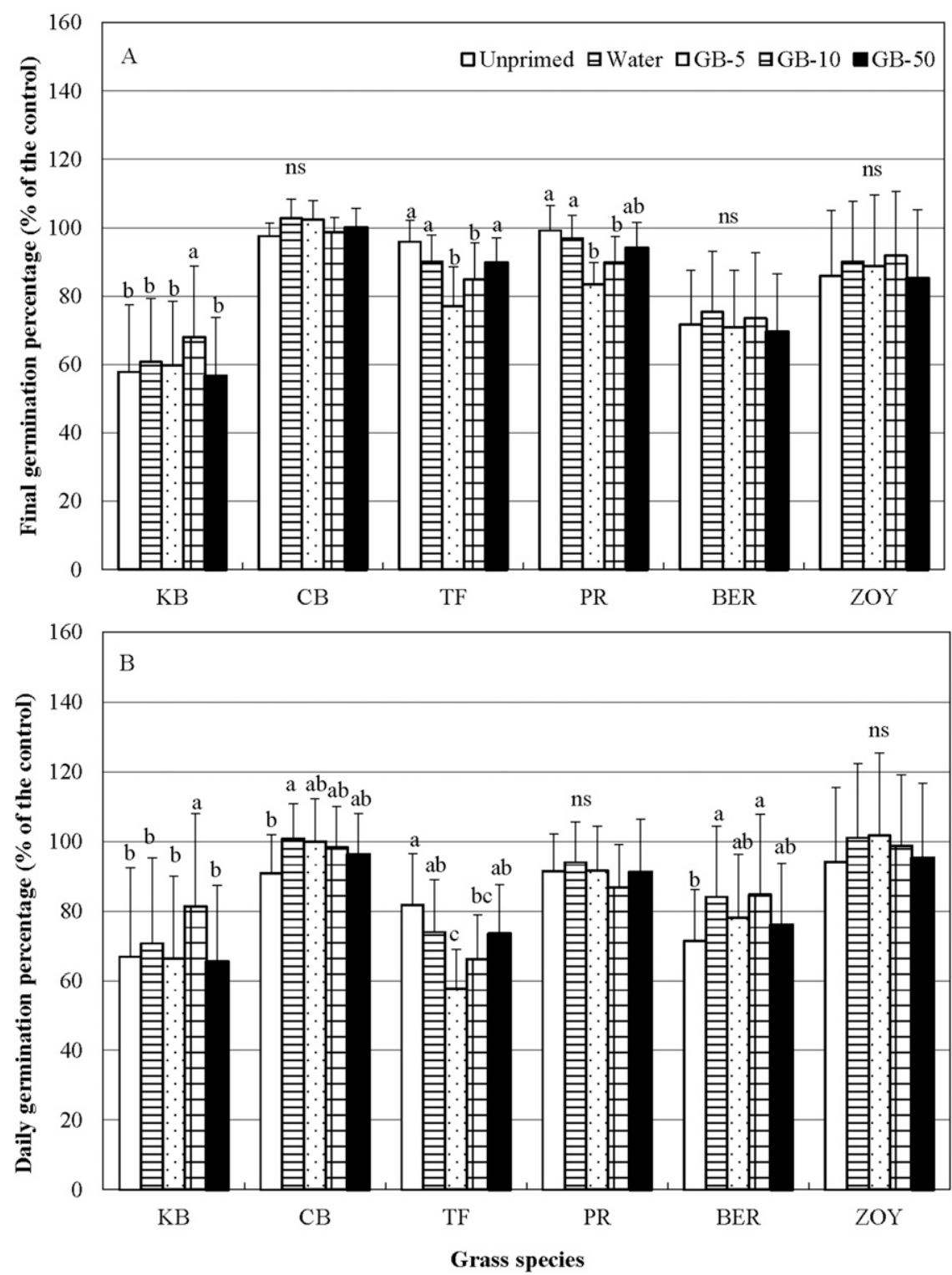

Fig. 3. Interactive effect of seed priming and turfgrass species on final germination percentage (A) and daily germination percentage $(\mathbf{B})$. Priming treatments included unprimed and primed at 5,10 , and $50 \mathrm{~mm}$ glycinebetaine (GB) or distilled water. Turfgrass species included perennial ryegrass (PR), tal fescue (TF), creeping bentgrass (CB), kentucky bluegrass (KB), bermudagrass (BER), and zoysiagrass (ZOY). The optimal germination temperature (OPT) for the cool-season (PR, TF, CB, and $\mathrm{KB}$ ) and warm-season (BER and ZOY) turfgrasses were $25 / 15^{\circ} \mathrm{C}$ (day/night) and $30 / 20^{\circ} \mathrm{C}$, respectively. Data were presented as percentage of the control (unprimed seeds germinated at OPT) of each species and averaged over temperatures. Means followed by the same letter in each species were not significantly different $(P \leq 0.05)$. Vertical bar indicates SD of individual mean.

a FGP of $56.2 \%$ of the control, significantly higher than other priming treatments (average $=$ $25.0 \%$ of the control) (data not shown). In contrast, seed priming had no effect on DGP (Table 2), averaging $37.7 \%$ of the control when data were pooled across grass species and drought conditions (data not shown).

Final germination percentage was significantly affected by the interaction between grass species and drought conditions (Table 2). Under non-stress conditions (0 MPa), PR had the highest FGP, followed by KB, TF, and $\mathrm{ZOY}$ (average $=103.6 \%$ of the control), and $\mathrm{CB}$ and BER had the lowest FGP (average = $95.4 \%$ of the control) (Fig. 1A). Under minor drought conditions $(-0.4 \mathrm{MPa}), \mathrm{KB}, \mathrm{BER}$, $\mathrm{ZOY}$, and $\mathrm{TF}$ showed a greater reduction of other factors (Table 2). The averaged FGP and DGP were $68.4 \%$ of the control and $58.2 \%$ of the control, respectively, when data were pooled across salinity and grass (data not shown).

Interactions between grass and salinity in FGP and DGP were observed (Table 2). At 5 to $10 \mathrm{dS} \cdot \mathrm{m}^{-1}, \mathrm{FGP}$ of $\mathrm{CB}, \mathrm{TF}$, and PR was not as affected as KB, ZOY, and BER (Fig. 2A). Perennial ryegrass and TF had a higher FGR (average $=94.0 \%$ of the control) at $15 \mathrm{dS} \cdot \mathrm{m}^{-1}$ followed by $\mathrm{CB}(62.4 \%$ of the control), whereas ZOY, BER, and KB had FGP dropped to less than $50 \%$ of the control. As the salinity level increased to $20 \mathrm{dS} \cdot \mathrm{m}^{-1}, \mathrm{CB}$ showed a lower FGP compared with PR and TF, which had a similar FGP as ZOY, BER, and $\mathrm{KB}$. A similar trend was observed in DGP in which PR, CB, and TF had higher DGP than the other grass species tested under low saline conditions, $5 \mathrm{dS} \cdot \mathrm{m}^{-1}$ (Fig. 2B). Creeping bentgrass had a similar DGP as TF at $10 \mathrm{dS} \cdot \mathrm{m}^{-1}$; however, TF outperformed CB as salinity levels increased to 15 and $20 \mathrm{dS} \cdot \mathrm{m}^{-1}$.

Expt. III: Priming effect on seed germination under temperature stress. A turfgrass $\times$ priming treatment interaction occurred in FGP and DGP (Table 2). The priming treatment did not affect FGP in CB, BER, and ZOY (Fig. 3A). Kentucky bluegrass seeds primed with GB at $10 \mathrm{~mm}$ had a higher FGP than other priming treatments (average $=58.7 \%$ of the control). The FGP of TF and PR increased with GB concentrations and seeds primed at $50 \mathrm{~mm}$ GB showed a similar level of FGR as the unprimed and hydroprimed seeds. The DGP of KB and BER was improved by $10 \mathrm{~mm}$ GB compared with the unprimed seeds (Fig. 3B). Hydroprimed CB seeds had a higher DGP than unprimed seeds, but not different from those primed with GB (average $=$ $98.2 \%$ of the control). In contrast, TF primed with 5 and $10 \mathrm{~mm} \mathrm{~GB}$ showed decreased DGP compared with the unprimed seeds. Perennial ryegrass and ZOY seeds did not respond to the priming treatments.

Interactions involving FGP and DGP between grass species and temperature occurred (Table 2). At OPT, grasses showed little variations in FGP (Fig. 4A). Chilling temperatures (OPT $-5^{\circ} \mathrm{C}$ and $\mathrm{OPT}-10^{\circ} \mathrm{C}$ ) had a limited effect on FGP in $\mathrm{CB}, \mathrm{TF}$, and $\mathrm{PR}$, whereas it reduced FGP by $46.9 \%$ and $88.0 \%$ in the other grasses at OPT $-5{ }^{\circ} \mathrm{C}$ and OPT $-10{ }^{\circ} \mathrm{C}$, respectively (Fig. 4A). Kentucky bluegrass had the highest FGP of all the grasses tested at OPT $+5{ }^{\circ} \mathrm{C}, 20 \%$ and $41 \%$ higher than $\mathrm{ZOY}$ and other grasses (average $=$ $95 \%$ of the control), respectively. As the temperature increased to $\mathrm{OPT}+10{ }^{\circ} \mathrm{C}$, differences in FGP further separated among the grasses; however, only KB had a FGP less than $50 \%$ of the control.

Tall fescue had a DGP of $82 \%$ of the control at OPT, which was significantly lower than other grasses (Fig. 4B). Creeping bentgrass and PR had a similar DGP at OPT $-5{ }^{\circ} \mathrm{C}$, followed by TF, and BER, ZOY, and $\mathrm{KB}$ had the lowest DGP. A similar trend was observed at OPT $-10{ }^{\circ} \mathrm{C}$. As the temperature increased from OPT to OPT $+5^{\circ} \mathrm{C}$, DGP of all grasses increased with the highest and lowest increase in $\mathrm{KB}$ and $\mathrm{TF}$, respectively. 

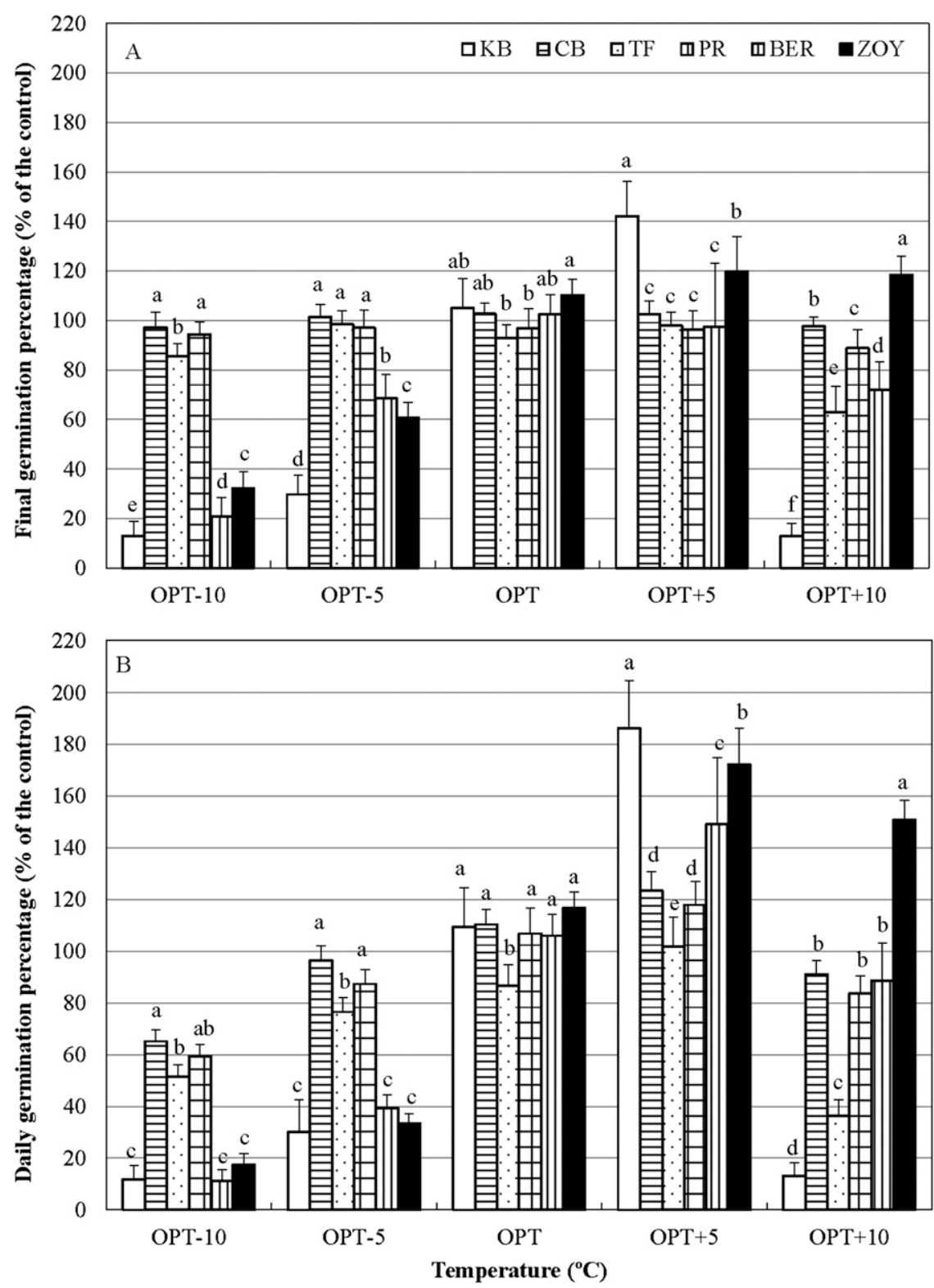

Fig. 4. Interactive effect of temperature and turfgrass species on final germination percentage (A) and daily germination percentage (B). Turfgrass species included perennial ryegrass (PR), tall fescue (TF), creeping bentgrass (CB), kentucky bluegrass (KB), bermudagrass (BER), and zoysiagrass (ZOY). The optimal germination temperature (OPT) for the cool-season (PR, TF, CB, and $\mathrm{KB}$ ) and warm-season (BER and ZOY) turfgrasses were $25 / 15^{\circ} \mathrm{C}$ (day/night) and $30 / 20{ }^{\circ} \mathrm{C}$, respectively. Data were presented as percentage of the control (unprimed seeds germinated at OPT) of each species and averaged over priming treatments. Means followed by the same letter in each species were not significantly different $(P \leq 0.05)$. Vertical bar indicates SD of individual mean.

At $\mathrm{OPT}+10{ }^{\circ} \mathrm{C}$, DGP of grasses decreased in the following order: $\mathrm{ZOY}>\mathrm{CB}$, $\mathrm{PR}$, and BER $>$ TF $>$ KB.

\section{Discussion}

Plants are more susceptible to stresses during the seed germination and seedling stages (Almansouri et al., 2001). In general, a decrease of FGP indicates reduced seed germination, whereas a decrease of DGP represents delayed germination of seeds. The results of this research showed that DGP is more sensitive to environmental stresses. For example, salinity stress caused an average of $47.3 \%$ and $33 \%$ decrease in
Plants experience a wide range of undesirable environmental conditions during their life cycle. Large inter- and intraspecific variations in stress tolerance exist in plants (Fry and Huang, 2004; Marcum, 2007). Cross-tolerance (i.e., plants resistant to one stress are often more resistant to others) may occur if the stressors induce similar damage and their signaling pathways converge (i.e., cross-talk) (Knight and Knight, 2001; Wang et al., 2003). For instance, drought, salinity, and extreme temperatures are manifested primarily as osmotic stress. Plants accumulated compatible solutes (e.g., carbohydrates, amino acids, and GB) under all three stresses to help stabilize proteins and cellular structures, maintain cell turgor, and remove excessive reactive oxygen species (Krasensky and Jonak, 2012). Ranking of relative tolerance of the six turfgrass species evaluated in the present were fairly consistent across drought, salinity, and suboptimal temperatures (except $\mathrm{OPT}+5{ }^{\circ} \mathrm{C}$ ), in which PR was a tolerant species followed by $\mathrm{TF}$ and $\mathrm{CB}$, and BER, ZOY, and $\mathrm{KB}$ were relatively stress-sensitive (Figs. 1, 2, and 4). Kentucky bluegrass had the highest FGP and DGP at $\mathrm{OPT}+5{ }^{\circ} \mathrm{C}$ of all grasses (Fig. 4), in contrast to its low tolerance to drought, salinity, and chilling temperature (OPT $-5^{\circ} \mathrm{C}$ and OPT $-10{ }^{\circ} \mathrm{C}$ ) (Figs. 1, 2, and 4). It might be because the $\mathrm{OPT}+5{ }^{\circ} \mathrm{C}$ temperature setting $\left(30 / 20{ }^{\circ} \mathrm{C}\right)$ remains within the optimum temperature range for $\mathrm{KB}$ seed germination $\left(16\right.$ to $30^{\circ} \mathrm{C}$ ) (Aldous, 1999 ) and its high thermal requirement for seed germination was met sooner at this higher temperature than others (Larsen and Bibby, 2005). As the temperature increased to OPT $+10{ }^{\circ} \mathrm{C}, \mathrm{KB}$ had the lowest FGP and DGP of all grasses (Fig. 4). Dai et al. (2009) and Zhang et al. (2011) reported that PR had high salinity tolerance followed by $\mathrm{TF}$ and $\mathrm{CB}$, and $\mathrm{KB}$ was salinity sensitive during germination, consistent with our findings. Fry and Huang (2004) reported that BER had the best drought tolerance (excellent) followed by ZOY and TF (very good) and KB (good), whereas $P R$ and $C B$ yielded fair drought tolerance. Bermudagrass and ZOY also had excellent tolerance to high temperatures followed by TF (good), CB and KB (medium), and PR (fair) (Beard, 1973). In contrast, CB and $\mathrm{KB}$ had excellent and good tolerance to low temperatures, respectively, followed by TF and ZOY (medium), whereas PR and BER were sensitive to low temperatures (Beard, 1973). The discrepancy between this study and other research may be caused by different evaluation stages: seed germination stage in the current study and vegetative growth stage in other research (Beard, 1973; Fry and Huang, 2004). Early reports showed that relative stress tolerance may differ between germination and vegetative growth (Dai et al., 2009; Wang et al., 2011; Zhang et al., 2013). Large intraspecific variations in stress tolerance may also contribute to the difference between the present research and other findings.

Farooq et al. (2008) reported that maize seeds soaked in 50,100 , and $150 \mathrm{mg} \cdot \mathrm{L}^{-1} \mathrm{~GB}$ 
enhanced chilling tolerance during germination and the seedling growth stage with the best results observed at $100 \mathrm{mg} \cdot \mathrm{L}^{-1}$, suggesting that GB had the potential of improving stress tolerance through seed priming. Results from Mahmood et al. (2009) showed that GB priming increased drought tolerance in three of five wheat cultivars and seeds primed at $50 \mathrm{~mm}$ GB performed better than those primed at 0 and $100 \mathrm{~mm}$. However, GB priming (at 10 and $30 \mathrm{~mm}$ ) had no influence on salinity tolerance of another two wheat cultivars in the research of Akhter et al. (2009). Such inconsistent results indicate that the efficacy of GB priming in stress enhancement is plant- (species/cultivar) and concentration-dependent. Zhang and Rue (2012) observed that GB (100 mM) priming increased FGP and seedling vigor of PR, $\mathrm{KB}, \mathrm{CB}$, and $\mathrm{TF}$ under the salinity stress. However, GB showed no influence on their germination under the same stress condition in the present study (Table 2). Low concentration of GB (less than $50 \mathrm{~mm}$ ) in this study might be one of the causes. In addition, both $\mathrm{NaCl}$ and $\mathrm{CaCl}_{2}$ were used to induce salinity in the present study, but only $\mathrm{NaCl}$ was used in the previous research (Zhang and Rue, 2012). The discrepancy between the two studies might also be caused by the different salt mixtures. A similar result was reported by $\mathrm{Yu}$ et al. (2013). They found that $\mathrm{CB}$ responded differently to $\mathrm{NaCl}$, $\mathrm{Na}_{2} \mathrm{CO}_{3}, \mathrm{Na}_{2} \mathrm{SO}_{4}$, and $\mathrm{CaCl}_{2}$ because the electrical conductivity, $\psi_{\mathrm{S}}$, and $\mathrm{pH}$ varied in these salt solutions. Furthermore, our results showed that six turfgrass species primed with the same levels of GB responded differently to drought, salinity, and suboptimal temperatures (Table 2; Figs. 1, 2, and 4). Iqbal and Ashraf (2005) suggested that the efficacy of seed priming varies under different stresses, priming agents, and plant species/cultivars. Ajouri et al. (2004) reported that primed barley seeds had a higher germination rate than the unprimed seeds after a 9-week storage at 4 ${ }^{\circ} \mathrm{C}$ under dark. Similar results were also observed by Powell et al. (2000) in which hydropriming improved germination of low vigor cauliflower seeds (B. Oleracea L. var. botrytis) (slow germinating and short shelf life) and such a positive effect of priming maintained up to 12 months. Fry et al. (1993) reported a faster establishment of hydroprimed buffalograss [Buchloë ductyloides (Nutt.) Engelm.] compared with unprimed seeds in the field. Rehman et al. (2011) reported that $\mathrm{CaCl}_{2}$-primed rice (Oryza sativa L.) seeds had reduced sterile spikelets and low abortive and chalky kernels and increased kernel nutrient content in a field experiment. Winter wheat germination and emergence were enhanced by seed priming under laboratory, greenhouse, and field conditions; however, seed priming showed no benefit for grain yield in the same study (Giri and Schillinger, 2003). Thus, further research should be conducted to validate the result of this research under field conditions.

\section{Literature Cited}

Ajouri, A., H. Asgedom, and M. Becker. 2004 Seed priming enhances germination and seedling growth of barley under conditions of $\mathrm{P}$ and Zn deficiency. J. Plant Nutr. Soil Sci. 167:630636.

Akhter, N., N.A. Akram, and M. Shabhaz. 2009. Presowing seed treatments with glycinebetaine and mineral nutrients of wheat (Triticum aestivum L.) under saline conditions. Pak. J. Agr. Sci. 44:236-241.

Aldous, D.E. 1999. International turfgrass management handbook. Butterworth Heinemann, Woburn, MA.

Almansouri, M., J.M. Kinet, and S. Lutts. 2001. Effect of salt and osmotic stresses on germination in durum wheat (Triticum durum Desf.). Plant Soil 231:243-254.

Ashraf, M. and M.R. Foolad. 2007. Roles of glycinebetaine and proline in improving plant abiotic stress resistance. Environ. Exp. Bot. 59:206-216.

Association of Official Seed Analysts. 2004. Rules for testing seeds. Association of Official Seed Analysts, Ithaca, NY.

Austin, R.B., P.C. Longden, and J. Hutchison. 1969. Some effects of 'hardening' carrot seed. Ann. Bot. (Lond.) 33:883-895.

Beard, J.B. 1973. Turfgrass: Science and culture. Prentice Hall, Englewood Cliffs, NJ.

Chen, T.H.H. and N. Murata. 2008. Glycinebetaine: An effective protectant against abiotic stress in plants. Trends in Plant Sci. Online. DOI: $10.1016 /$ j.tplants.2008.0607.

Chinnusamy, V., A. Jagendorf, and J. Zhu. 2005. Understanding and improving salt tolerance in plants. Crop Sci. 45:437-448.

Dai, J., D.R. Huff, and M.J. Schlossberg. 2009. Salinity effects on seed germination and vegetative growth of greens-type Poa annua relative to other cool-season turfgrass species. Crop Sci. 49:696-703.

Emmerich, W.E. and S.P. Hardegree. 1991. Seed germination in polyethylene glycol solution: Effects of filter paper exclusion and water vapor loss. Crop Sci. 31:454-458.

Farooq, M., T. Aziz, M. Hussain, H. Rehman, K. Jabran, and M.B. Khan. 2008. Glycinebetaine improves chilling tolerance in hybrid maize. J. Agron. Crop Sci. 194:152-160.

Farooq, M., S.M.A. Basra, and K. Hafeez. 2006. Seed invigoration by osmohardening in coarse and fine rice. Seed Sci. Technol. 34:181-187.

Fry, J. and B. Huang. 2004. Applied turfgrass science and physiology. John Wiley \& Sons, Inc., Hoboken, NJ.

Fry, J., W. Upham, and L. Leuthold. 1993. Seeding month and seed soaking affect buffalograss establishment. HortScience 28:902-903.

Giri, G.S. and W.F. Schillinger. 2003. Seed priming winter wheat for germination, emergence, and yield. Crop Sci. 43:2135-2141.

Gray, D. and J.R.A. Steckel. 1977. Effects of presowing treatments on the germination and establishment of parsnips. J. Hort. Sci. Biotechnol. 52:525-534.

Horst, G.L. and N.B. Dunning. 1989. Germination and seedling growth of perennial ryegrass in soluble salts. J. Amer. Soc. Hort. Sci. 114:338342 .

Hu, X., T. Hu, X. Zhang, H. Pang, and J. Fu. 2012. Exogenous glycine betaine ameliorates the adverse effect of salt stress on perennial ryegrass. J. Amer. Soc. Hort. Sci. 137:38-46.

Iqbal, M. and M. Ashraf. 2005. Changes in growth, photosynthetic capacity and ionic relations in spring wheat (Triticum aestivum L.) due to presowing seed treatment with polyamines Plant Growth Regulat. 46:19-30.

Kaya, M.D., G. Okçu, M. Atak, Y. Çikili, and Ö. Kolsarici. 2006. Seed treatments to overcome salt and drought stress during germination in sunflower (Helianthus annuus L.). Eur. J. Agron. 24:291-295.

Knight, H. and M. Knight. 2001. Abiotic stress signaling pathways specificity and cross-talk. Trends Plant Sci. 6:262-267.

Krasensky, J. and C. Jonak. 2012. Drought, salt, and temperature stress-induced metabolic rearrangements and regulatory networks. J. Expt. Bot. 63:1593-1608.

Larsen, S.U. and B.M. Bibby. 2005. Differences in thermal time requirement for germination of three turfgrass species. Crop Sci. 45:2030 2037.

Li, X., Y.Q. Yang, M. Zhang, and X.F. Wang. 2010. Effect of PEG priming on plasma membrane $\mathrm{H}^{+}$-ATPase activities and mitochondrium function in soybean seeds. Seed Sci. Technol. 38:49-60.

Mahmood, T., M. Ashraf, and M. Shahbaz. 2009. Does exogenous application of glycinebetaine as a pre-sowing seed treatment improve growth and regulate some key physiological attributes in wheat plants grown under water deficit conditions? Pak. J. Bot. 41:12911302.

Marcum, K.B. 2007. Physiological adaptations of turfgrasses to salinity stress, p. 404-417. In: Pessarakli, M. (ed.). Handbook of turfgrass management and physiology. Taylor Francis Group, LLC, Boca Raton, FL.

McCarty, L.B. and A.E. Dudeck. 1993. Salinity effects on bentgrass germination. HortScience 28:15-17.

Michel, B.E. and M.R. Kaufmann. 1973. The osmotic potential of polyethylene glycol 6000. Plant Physiol. 51:914-916.

Naidu, B.P., L.G. Paleg, D. Aspinall, A.C.C. Jennings, and G.P. Jones. 1991. Amino acid and glycine betaine accumulation in coldstressed wheat seedlings. Phytochemistry 30:407-409.

Nomura, M., Y. Muramoto, S. Yasuda, T. Takabe, and S. Kishitani. 1995. The accumulation of glycinebetaine during cold acclimation in early and late cultivars of barley. Euphytica 83:247250 .

Park, E.J., Z. Jeknic, and T.H. Chen. 2006. Exogenous application of glycinebetaine increases chilling tolerance in tomato plants. Plant Cell Physiol. 47:706-714.

Peel, M.D., B.L. Waldron, K.B. Jensen, N.J. Chatterton, H. Horton, and L.M. Dudley. 2004. Screening for salinity tolerance in alfalfa: A repeatable method. Crop Sci. 44:2049-2053.

Powell, A.A., L.J. Yule, H. Jing, S.P.C. Groot, R.J. Bino, and H.W. Pritchard. 2000. The influence of aerated hydration seed treatment on seed longevity as assessed by the viability equations. J. Expt. Bot. 51:2031-2043.

Rehman, H.U., S.M.A. Basra, and M. Farooq. 2011. Field appraisal of seed priming to improve the growth, yield, and quality of direct seeded rice. Turk. J. Agr. For. 35:357-365.

Sakamoto, A. and N. Murata. 1999. Genetic engineering of glycinebetaine synthesis in plants: Current status and implications for enhancement of stress tolerance. J. Expt. Bot. 51:81-88.

Wang, S., Q. Zhang, and E. Watkins. 2011. Evaluation of salinity tolerance of prairie junegrass, a potential low-maintenance turfgrass species. HortScience 46:1038-1043.

Wang, W., B. Vinocur, and A. Altman. 2003. Plant responses to drought, salinity and extreme 
temperatures: Towards genetic engineering for stress tolerance. Planta 218:1-14.

Weimberg, R., H.R. Lerner, and A. PoljakoffMayber. 1984. Changes in growth and water soluble solute concentrations in Sorghum bicolor stressed with sodium and potassium. Physiol. Plant. 62:472-480.

Yang, Z., J. Yu, E. Merewitz, and B. Huang. 2012. Differential effects of abscisic acid and glycine betaine on physiological responses to drought and salinity stress for two perennial grass species. J. Amer. Soc. Hort. Sci. 137:96-106.
Yu, Q., Z. Chang, and D. Li. 2013. Physiological responses of creeping bentgrass cultivars to carbonate, chloride, and sulfate salinity. Crop Sci. 53:1734-1742.

Zhang, Q. and K. Rue. 2012. Glycinebetaine seed priming improved osmotic and salinity tolerance in turfgrasses. HortScience 47:11711174.

Zhang, Q., K. Rue, and S. Wang. 2012. Salinity effect on seed germination and growth of two warm-season native grass species. HortScience 47:527-530.
Zhang, Q., S. Wang, and K. Rue. 2011. Salinity tolerance of 12 turfgrasses in three germination media. HortScience 46:651-654.

Zhang, Q., A. Zuk, and K. Rue. 2013. Salinity tolerance of nine fine fescue cultivars compared to other cool-season turfgrasses. Sci. Hort. 159:67-71.

Zheng, G.H., R.W. Wilen, A.E. Slinkard, and L.V. Gusta. 1994. Enhancement of canola seed germination and seedling emergence at low temperature by priming. Crop Sci. 34:15891593. 